\title{
Neuropsychological Functioning in Unilateral Cerebellar Damage
}

\author{
Thérèse Botez-Marquard, Jean Léveillé and M.I. Botez
}

\begin{abstract}
A woman had a left superior cerebellar artery infarct associated with reduced hexamethylpropileneamine oxime uptake on SPECT scan of the basal ganglia and frontoparietal areas of the opposite hemisphere performed poorly in some neuropsychological tests indicating right hemisphere dysfunction. There was a lengthening of reaction and movement times with the hand ipsilateral to the lesion. These deficits were temporary. A unilateral cerebellar lesion can produce neuropsychological deficits, possibly because of hypoperfusion in contralateral frontoparietal regions, but spontaneous neuropsychological remissions may occur.
\end{abstract}

Résumé: Fonction neuropsychologique avec une lésion cérébelleuse unilatérale. Il s'agit d'une patiente ayant eu un accident cérébro-vasculaire suite à une thrombose de l'artère cérébelleuse supérieure et qui a présenté une diaschisis cérébello-corticale à la scintitomographie (SPECT) avec hexamethylpropileneamine oxime (HMPAO). L'évaluation neuropsychologique a été suggestive d'une dysfonction frontopariétale droite, la même localisation que celle de l'hypoperfusion constatée au SPECT. Une lésion cérébelleuse unilatérale peut déterminer des déficits suggestifs d'une dysfonction neuropsychologique frontopariétale contralatérale en présence d'un scan normal.

Can. J. Neurol. Sci. 1994; 21: 353-357

The role of the human cerebellum in non-motor behavior is an emerging concept in full development. After our initial description of neuropsychological disorders determined by bilateral cerebellar lesions, ${ }^{1}$ papers from our laboratory and elsewhere ${ }^{2-11}$ drew attention to the occurrence of specific neuropsychological deficits with bilateral cerebellar injury. In contrast, there are few reports ${ }^{12-14}$ of neuropsychological assessment in patients with unilateral cerebellar damage.

Cerebello-cortical diaschisis has been detected by single photon emission computed tomography (SPECT): $:^{3.15 .16}$ after a unilateral cerebellar infarct, hexamethylpropyleneamine oxime (HMPAO) hypoperfusion may be observed in the contralateral frontoparietal cortex despite a normal CT scan at the cortical level. ${ }^{3.16}$

The aim of this case report was two-fold: i) to evaluate neuropsychological performance in a patient with a very welldelimited cerebellar infarct; and ii) to assess if neuropsychological shortfalls, if any, correspond to a deficit usually considered to be induced by lesions of the cerebral hemisphere contralateral to the cerebellar insult.

\section{Case Report}

L.P., a 64-year-old right-handed woman with 12 years of education, was treated for high blood pressure for 20 years. She was admitted to the Neurology Service for dizziness of sudden onset, nausea, vomiting and ataxia. Neurological examination revealed moderate gait ataxia and a moderate left-sided cerebellar syndrome documented by deficient finger-nose-finger and heel-to-knee tests as well as adiadochokinesia with the left hand. She had bilateral brisk tendon reflexes; her plantar reflexes were flexor. There were no other neurological abnormalities. After 2 days, the nausea and vomiting disappeared. The left cerebellar syndrome persisted, but improved slightly in the course of a few months.

Both CT scan and magnetic resonance imaging (MRI) showed a hypodense area in the medial, anterior and superior region of the left cerebellar hemisphere compatible with recent softening of the left superior cerebellar artery. There were no supratentorial lesions on both CT scans and MRI (Figure IA and 1B). SPECT was undertaken as described previously. ${ }^{16}$ We used a color scale with $10 \%$ step variations per color, ranging from $100 \%$ to $90 \%$ for white to $10 \%$ to $0 \%$ for blue. Similarly to other patients with unilateral cerebellar infarcts, ${ }^{15.16}$ crossed cerebello-cortical diaschisis was observed: reduced left cerebellar HMPAO uptake (corresponding to the cerebellar infarct on CT scans and MRI) was accompanied by a significant $(30 \%)$ decrease of HMPAO uptake in the basal ganglia and frontoparietal cortex of the opposite (i.e right) hemisphere (Figure $2 \mathrm{~A}, \mathrm{~B}, \mathrm{C}$ and $\mathrm{D})$.

Neuropsychological evaluation was based on our previous studies of bilateral lesions ${ }^{1-3,9,10}$ which detected slowed information processing with parietal and frontal-like deficits. Therefore, our aim was to assess:

From the Laboratory of Neurobiology, Neurology Service, Hôtel-Dieu de Montréal and Faculty of Medicine, University of Montréal, Montréal.

RECEIVED NOVEMBER 10. 1993. ACCEPTED IN FINAL FORM MAY 9. 1994

Reprint requests to: Thérèse Botez-Marquard, Laboratory of Neurobiology, Neurology Service, Hôtel-Dieu de Montréal. 3840 St. Urbain Street. Montréal. Québec, Canada H2W IT8 
A.

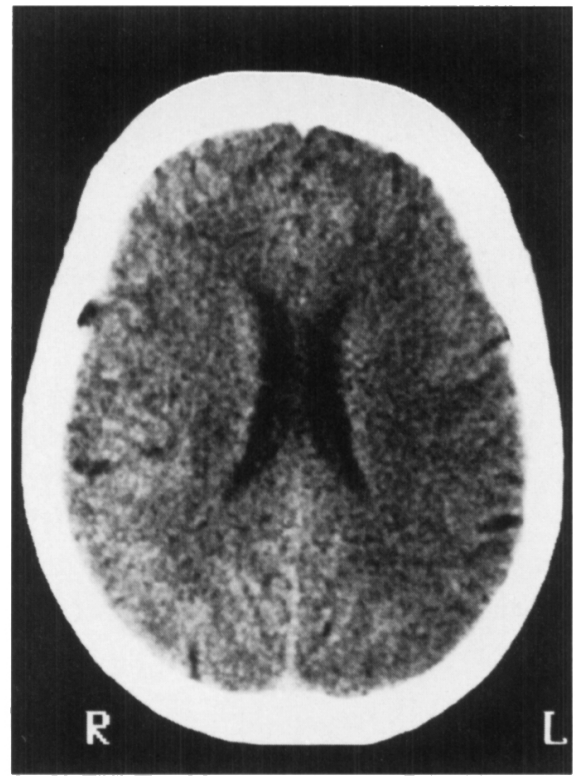

B.

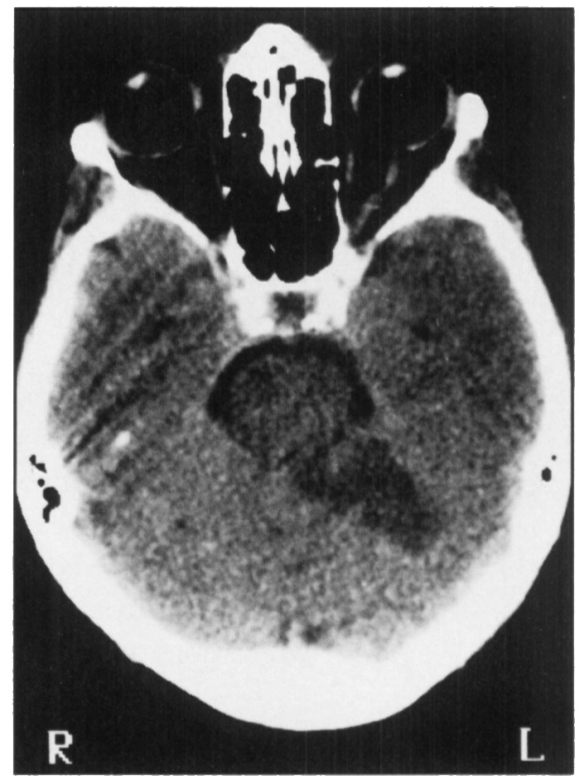

Figure 1A, 1B: CT scan of the brain. Cerebellar softening involving the lefi superior cerebellar artery with no other cerebral or cerebellar damage.
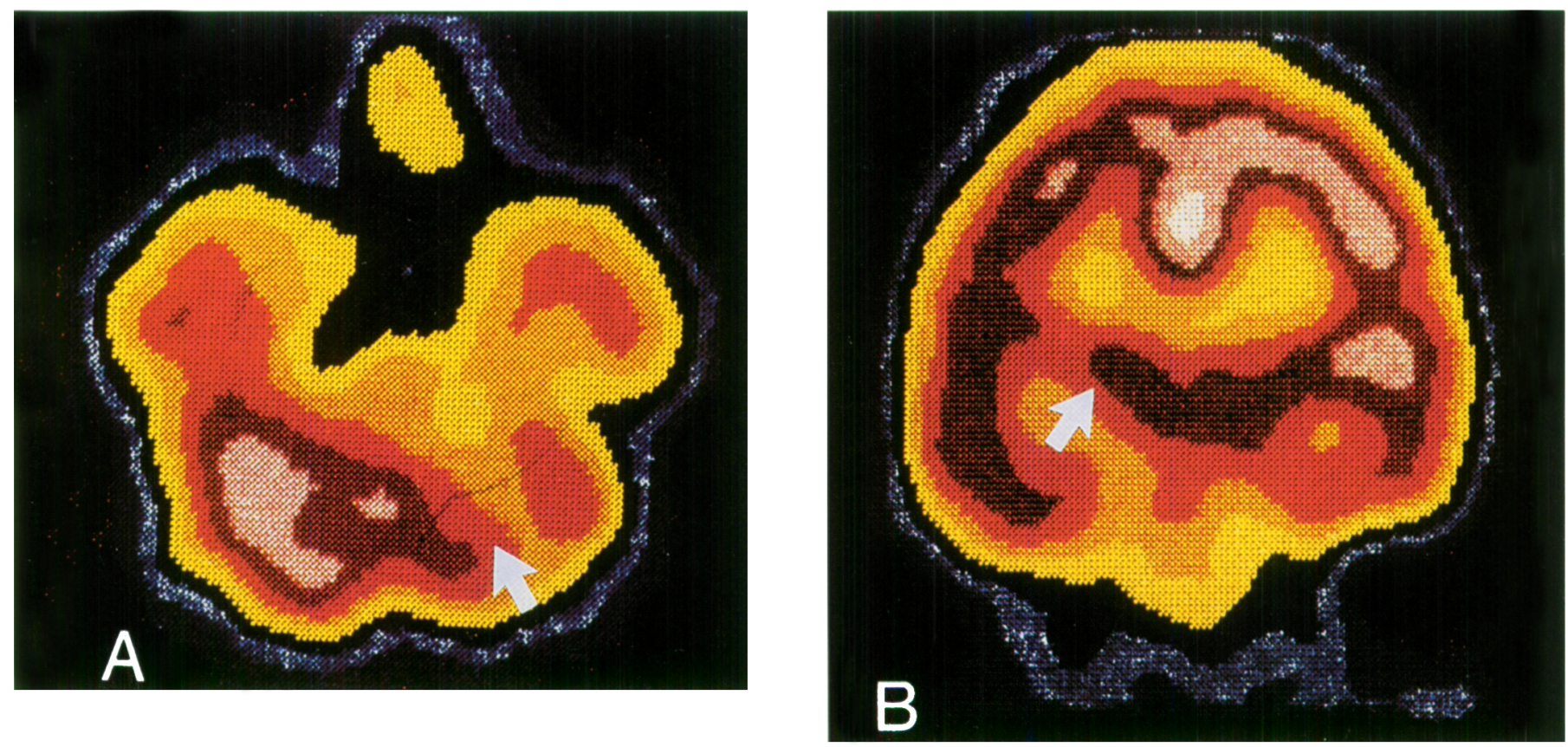

Figure 2: Same patient as in Figure 1. SPECT study. A: transverse cerebellar level slice. Reduced left unilateral cerebellar Tc ${ }^{99 m}$ HMPAO uptake (by 50\%). B: coronal cortical and basal ganglia level slice. Reduced right cortical and right basal ganglia uptake (by 30\%).

1) general intelligence with the Ottawa-Wechsler IQ scale and Raven's standard progressive matrices); 2) frontal and parietal lobe functions, language abilities (the Wisconsin card sorting test, verbal naming, phonemic and categorial fluency, Hooper's visual organization test, Benton's judgment of line orientation test, Rey's Oesterreith complex figure test); and 3) simple reaction time (RT) as well as multiple choice reaction time (MCRT) to measure information processing.

Simple forewarned visual RT (SVRT) and MT were measured with a Philips (768K) micro-computer and a cathode ray tube monitor (amber and black) was used to project visual stimuli. Three telegraph keys mounted on a wooden board were connected to the micro-computer. The basic method was programmed as described elsewhere. ${ }^{2}$ However, one change was made to it. With simple RT (SRT), the red centrallylocated stimulus was replaced by 2 simultaneously appearing yellow arrows on each side of the screen. The program was started with SVRT I, keeping RT and MT (the distance) constant and then continuing with multiple-choice RT (MCRT II and III), making the tasks slightly more difficult in order to evaluate the effect of increased cognitive loading on procedural learning, fast screening memory, and visuo-spatial functions.

The RT results were computed for each block ( $X, S D$, number of errors and valid trials). To conduct 18 valid trials for SRT and 36 for MCRT, RTs had to be no faster than $100 \mathrm{msec}$ and no slower than 1000 msec. The same criteria were used for MTs; otherwise, they were immediately discarded and simply added as "invalid" RT or MT trials. Each block was preceded by 5 trials to familiarize the subjects with the procedure. The examiner verified that the task was well understood, giving appropriate feedback if necessary. 

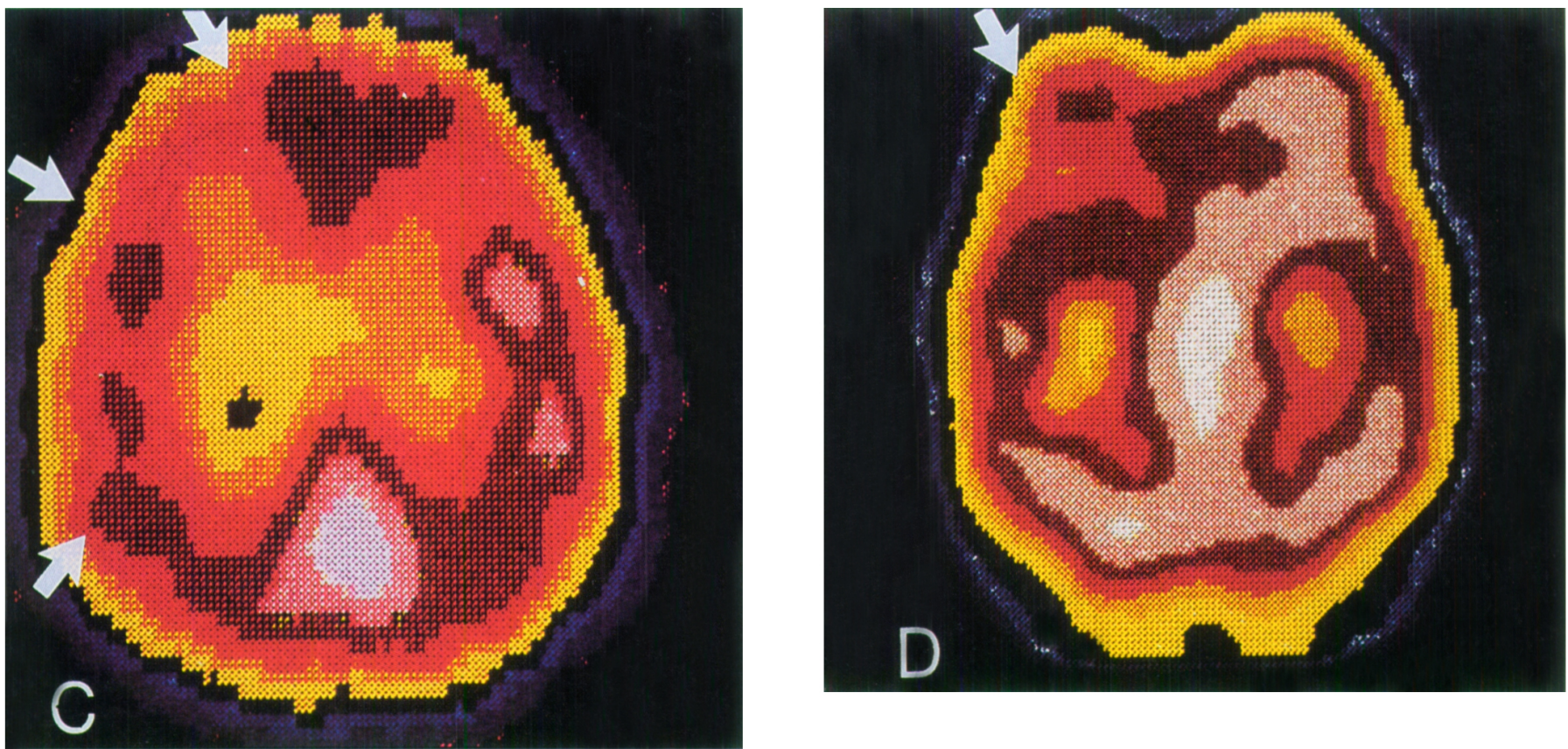

Figure 2: C: transverse mild cortical level slice. Right frontoparietal uptake reduced significantly (by 30\%). D: Transverse upper cortical level slice. Significant right frontal uptake reduction (by 30\%).

To proceed, the subject pressed the central button, making the warning visual signal (a centrally-placed yellow dot) appear. There was a latency period which varied randomly from 2 to $4 \mathrm{sec}$. Upon appearance of the stimulus, the subject lifted his or her index finger (RT) and pressed the right or left key (MT) depending on the task. In SVRT I, the patient had to release the middle key on the appearance of 2 arrows flashed simultaneously on both the right and left sides of the screen, with instructions to move to the right-sided key with the right hand (MT I). In the first MCRT task (MCRT II), the arrow appeared either on the right or left side (MT II). In MCRT III, a geometric octagonal figure appeared simultaneously with a cross (octagon on the left, cross on the right side of the screen). The subject was instructed to remember the position of each symbol since they would subsequently appear in the center of the screen and he/she would have to press the left key when the octagon appeared or the right key (MT III) when the cross appeared. All RT and MT tasks were performed with the right and left hand.

The first neuropsychological evaluation was undertaken when the patient's condition had stabilized and when she was free of nausea, i.e, 2 weeks after the onset of symptoms. Patient cooperation was excellent. The second evaluation took place more than 2 years later (Table 1). RT performances were repeated more frequently (Table 2 ).

Her speech was fluent, with no difficulties observed in word finding, word comprehension, proverb interpretation, reading or writing. No ideomotor or ideational apraxia was present.

Table 1 reveals superior verbal IQ performance (129) and remarkably diminished performance IQ in the first assessment (97). The second assessment shows a significant improvement of performance IQ (115), particularly the picture arrangement (logical judgment of sequences in familiar situations) and digit symbol subtests. Benton's judgment of line orientation test (a non-motor visuo-spatial test) and Hooper's visual organization test (a concept formation task) were also improved during the second assessment. The Wechsler memory scale showed homogenous results and superior global performance that may be considered unchanged on second evaluation.

On Rey's 15 auditory word learning list, the patient showed no difficulty with any modality and performed well. Verbal fluency only for phonemic generation of three letters was deficient but improved on the second assessment. Category fluency was always well above normal values. Performance of the Wisconsin card sorting test was normal on all parameters (data not shown). Rey's Osterrieth complex figure test was much better organized during the second assessment. The first time she started off with the central rectangle and division of the diagonal cross. This was followed by details of the rectangle which was not a logical decision in order to keep the proportions in line. However, the copy of the complete design was well recognizable with a precision score of 27. She had maximum scores on both performances of Raven's standard progressive matrices.

Table 1. Neuropsychological Tests.

\begin{tabular}{|c|c|c|c|}
\hline Ottawa-Wechsler & January 1991 & May 1993 & Norms \\
\hline Global IQ* & 119 & 125 & 100 \\
\hline Verbal IQ* & 128 & 125 & 100 \\
\hline Performance IQ* & 97 & 115 & 100 \\
\hline Information & 17 & 17 & 19. \\
\hline Comprehension & 19 & 18 & $19 \%$ \\
\hline Digit span & 13 & 10 & 19: \\
\hline Arithmetic & 15 & 15 & 170 \\
\hline Similarities & 16 & 16 & 200 \\
\hline Picture arrangement & 5 & 14 & 180 \\
\hline Picture completion & 13 & 13 & $16 \mathrm{C}$ \\
\hline Block design & 11 & 10 & $20 \div$ \\
\hline Object assembly & 8 & 9 & 172 \\
\hline Digit symbol & 8 & 10 & 16 \\
\hline Wechsler memory scale & 134 & 130 & 100 \\
\hline $\begin{array}{l}\text { Raven standard progressive } \\
\text { matrices }\end{array}$ & $99^{\circ}$ & $99^{\circ}$ & $>99^{\circ}$ \\
\hline Pillon's object recognition test & (2) 13 & (2) 11 & 15 \\
\hline Rey's Osterrieth complex figure & $27[18]$ & $34[21]$ & $<32$ \\
\hline $\begin{array}{l}\text { Benton's judgment of line } \\
\text { orientation }\end{array}$ & 19 & 22 & $<170$ \\
\hline 15-word list learning (list A) & $8,9,11,13,14$ & $8,11,12,15,15$ & 75 \\
\hline Interference (list B) & 7 & 6 & $6-8$ \\
\hline Proactive recall (list A) & 14 & 15 & $9-12$ \\
\hline Delayed recall (list $\mathbf{A}$ ) & 14 & 15 & $10-14$ \\
\hline Recognition (list A) & 15 & 15 & $13-15$ \\
\hline Verbal fluency FAS (3 min.) & 25 & 45 & $<310$ \\
\hline Verbal fluency categories & 43 & 49 & $<38$ \\
\hline Hooper visual organization test & 16.5 & 23 & $<23 a$ \\
\hline Smedley grip-strength right hand & $20 \mathrm{~kg}$ & $19 \mathrm{~kg}$ & $15-22 \mathrm{~kg}$ \\
\hline Smedley grip-strength left hand & $17 \mathrm{~kg}$ & $17 \mathrm{~kg}$ & $15-22 \mathrm{~kg}$ \\
\hline $\begin{array}{l}\text { Percentiles } \\
\text { () Time allowance } 2 \text { min. } \\
\text { - Cut-off score }\end{array}$ & \multicolumn{3}{|c|}{$\begin{array}{l}\text { * Age adjusted for } 59 \text {-year-olds } \\
0 \text { Scaled score } \\
\text { [ ] Delayed memory }\end{array}$} \\
\hline
\end{tabular}


Table 2. Reaction Time Performance of patient and control values (means and SD).

\begin{tabular}{|c|c|c|c|c|c|c|c|c|}
\hline & \multicolumn{2}{|c|}{ January 1991} & \multicolumn{2}{|c|}{ July 1992} & \multicolumn{2}{|c|}{ May 1993} & \multicolumn{2}{|c|}{ Normal values $(N=15)$} \\
\hline $\begin{array}{l}\text { SVRT I (msec) } \\
\text { Right hand (RH) } \\
\text { Left hand }(\mathrm{LH})\end{array}$ & $\begin{array}{l}366(153) \\
425(142)\end{array}$ & $\begin{array}{l}251(153) \\
362(138)\end{array}$ & $\begin{array}{l}252(92) \\
302(70)\end{array}$ & $\begin{array}{l}161(29) \\
187(33)\end{array}$ & $\begin{array}{l}279(61) \\
278(61)\end{array}$ & $\begin{array}{l}179(74) \\
187(74)\end{array}$ & $240(35)$ & $179(21)$ \\
\hline $\begin{array}{l}\text { MCRT II (msec) } \\
\text { Right hand (RH) } \\
\text { Left hand (LH) }\end{array}$ & $\begin{array}{l}389(133) \\
499(130)\end{array}$ & $\begin{array}{l}280(78) \\
382(137)\end{array}$ & $\begin{array}{l}316(59) \\
328(80)\end{array}$ & $\begin{array}{l}208(86) \\
227(39)\end{array}$ & $\begin{array}{l}298(38) \\
311(58)\end{array}$ & $\begin{array}{l}186(32) \\
223(68)\end{array}$ & $309(55)$ & $185(42)$ \\
\hline $\begin{array}{l}\text { MCRT III (msec) } \\
\text { Right hand (RH) } \\
\text { Left hand (LH) }\end{array}$ & $\begin{array}{l}425(131) \\
529(102)\end{array}$ & $\begin{array}{l}331(127) \\
364(132)\end{array}$ & $\begin{array}{l}416(75) \\
397(86)\end{array}$ & $\begin{array}{l}230(73) \\
312(104)\end{array}$ & $\begin{array}{l}384(73) \\
343(62)\end{array}$ & $\begin{array}{l}224(63) \\
281(05)\end{array}$ & $385(50)$ & $203(46)$ \\
\hline
\end{tabular}

Legends:

SVRT I = simple visual reaction time (arrow left and right side simultaneously)

MCRT II = multiple choice reaction time (arrow on left or right side)

MCRT III = multiple choice reaction time (octagon left side/cross right side)

All RT measurements were slow on initial testing for both hands but gradually improved over time improved (Table 2). MT with the left hand ipsilateral to the left cerebellar hemisphere remained slower than with the right hand throughout the different testing periods.

\section{Discussion and Conclusions}

Neuropsychological assessment revealed right hemisphere dysfunction manifested by a significant discrepancy between verbal versus performance IQ testing, particularly in subtests of object assembly, picture arrangement, digit symbol, Hooper's visual organization test and Benton's judgment of line orientation. Frontal-like deficiencies were displayed by low performances in picture arrangement, phonemic verbal fluidity and Rey's Osterrieth complex figure test.

Nevertheless, considerable improvement was noted over time on all the above-mentioned low neuropsychological performances and RT measurements. However, CT scans, MRI and SPECT remained unchanged.

Among three papers ${ }^{12-14}$ dealing with neuropsychological performance in unilateral cerebellar damage, two were biased as follows: in the report by Wallesch and Horn, ${ }^{12}$ of the 12 patients studied, 11 had tumors and shunting procedures done for hydrocephalus; in the article by Akshoomoff et al., ${ }^{13}$ the patient had mild parietal and occipital atrophy. In the case reported by Fiez et al., ${ }^{14}$ a mild neuropsychological left hemisphere syndrome (a disorder of specific verbal abilities) was observed after a right cerebellar infarct. No SPECT or PET was undertaken in these studies. ${ }^{12-14}$

The first conclusion to be drawn from this case report is that the cerebello-cortical diaschisis following a left cerebellar infarct is accompanied not only by right basal ganglia and frontoparietal HMPAO hypoperfusion but also by a mild right frontoparietal neuropsychological deficit. We can therefore assume that unilateral cerebellar infarcts with cerebellar-basal ganglia-cortical diaschisis are associated with minor neuropsychological deficiencies indicative of contralateral cerebral hemisphere involvement.

The second conclusion is that the neuropsychological findings as well as the RT measurements became normal after 8-12 months despite persistent cerebello-cortical diaschisis on SPECT. ${ }^{3.15 .16}$ Experimental findings are in agreement with our data. For example, unilateral dentate lesions in monkeys induced lengthened RT in the immediate post-lesion period; auditory RT gradually declined over about 20 days post-operatively, approaching normal values. ${ }^{17}$

\section{ACKNOWLEDGEMENTS}

This study was supported by grants from the Du Pont Merck Pharmaceutical Company, Wilmington, Delaware, USA and the Canadian Association of Friedreich's Ataxia. Thanks are due to Mrs. Michèle Mathieu for her secretarial help and Mr. Ovid Da Silva for editorial assistance.

\section{REFERENCES}

1. Botez MI, Gravel J, Attig E and Vézina JL. Reversible chronic cerebellar ataxia after phenytoin intoxication: possible role of cerebellum in cognitive thought. Neurology 1985; 35: 11521157.

2. Botez MI, Botez T, Elie R and Attig E. Role of the cerebellum in complex human behavior. Ital J Neurol Sci 1989; 10: 291-300.

3. Botez MI, Léveillé $J$ and Botez $T$. Role of the cerebellum in cognitive thought: SPECT and neurological findings. $I n$ : M. Matheson and H. Newman, eds. Rehabilitation: The Path Back, Australian Society for the Study of Brain Impairment, Richmond, Australia, 1989.

4. Bracke-Tolkmitt R, Linden A, Canavan AGM, et al. The cerebellum contributes to mental skills. Behav Neurosci 1989; 103: 442-446.

5. Kish S, El-Awar M, Schut L, et al. Cognitive deficits in olivopontocerebellar atrophy: implications for the cholinergic hypothesis of Alzheimer dementia. Ann Neurol 1988; 24: 200-206.

6. Appollonio IM, Grafman J, Schwartz V, Massaquoi S and Hallett $M$. Memory in patients with cerebellar degeneration. Neurology 1993; 43: 1536-1544.

7. El-Awar M, Kish S, Oscar-Berman M, et al. Selected delayed alternation deficits in dominantly inherited olivopontocerebellar atrophy. Brain Cogn 1991; 16: 121-129.

8. Hirono N, Yamadori N, Kameyama M, Mezaki T and Abe K. Spinocerebellar degeneration (SCD): cognitive disturbances. Acta Neurol Scand 1991; 84: 226-230.

9. Botez MI. The neuropsychology of the cerebellum: an emerging concept. Arch Neurol 1992; 49: 1229-1230.

10. Botez-Marquard T and Botez MI. Cognitive behavior in heredodegenerative ataxias. Eur Neurol 1993; 33: 351-357.

11. Grafman J, Litvan I, Massaquoi S, et al. Cognitive planning deficit in patients with cerebellar atrophy. Neurology 1992; 42: 14931496. 
12. Wallesch $\mathrm{CW}$ and Horn $\mathrm{A}$. Long-term effects of cerebellar pathology on cognitive functions. Brain Cogn 1990; 14: 19-25.

13. Akshoomoff NA, Courchesne E, Press GA and Iragui V. Contribution of the cerebellum to neuropsychological functioning: evidence from a case of cerebellar degenerative disorder. Neuropsychologia 1992; 30: 315-338.

14. Fiez JA, Petersen SE, Cheney MK and Raichle ME. Impaired nonmotor learning and error detection associated with cerebellar damage. Brain 1992; 115: 155-178.
15. Broich K, Hartmann A, Biersack HJ and Horn R. Crossed cerebellocerebral diaschisis in a patient with cerebellar infarction. Neurosci Lett 1987; 83: 7-12.

16. Botez Ml, Léveillé J, Lambert R and Botez T. Single photon emission computed tomography (SPECT) in cerebellar disease: cerebello-cerebral diaschisis. Eur Neurol 1991; 31: 405-412.

17. Amrani K, Pellerin JP and Lamarre Y. The effect of bilateral lesions of the cerebellar nuclei on motor performance in the monkey. Soc Neurosci Abstr 1988; 13: 1239. 